\title{
A Linguistic Analysis of Posuban as a Material Culture: The Case of Amamoma, Apewosika and Kwaprow
}

\author{
Catherine Ekua Mensah
}

\author{
OLA College of Education, Languages Department, Cape Coast
}

\begin{abstract}
The purpose of the study was to find out the interpretations of colours and symbols on the Posuban as well as interpretations of the inscriptions on Posuban as an object of material culture and identity. The study employed a qualitative research design. Observation and interview were the instruments used to collect data for the study. From the linguistic perspective of colours, drawings/images and inscriptions it was revealed that, Posuban tells a lot about Fante peoples' history, beliefs, values and their character which remain otherwise inaccessible except through impersonal records. It was also revealed that Posuban is emblematic, iconic and indexical. It is therefore recommended that, more studies should be done on Posuban. This is because, today, Posuban are merely considered as shrines but there are a lot of scholarly information that could be obtained from this Posuban for studies in so many disciplines.
\end{abstract}

Keywords: Posuban, Language, Culture, Material Culture, Semiotics

\section{Introduction}

The material objects produced by the hand of a man or used by him is one of the clearest expressions of mental process that we have. The perception of physical things depends primarily upon man's tactile and visual faculties and of language upon audition. But in the acquisition of knowledge in either realm, these two faculties cannot be separated. Throughout history, human societies have been confronted with the permanence of the manifestations of their own past, the manifestations which made up the physical framework of their own present. These are the monuments and objects, but also landscapes and places, which make up the materials that make it possible for societies to construct and maintain their identity (Alcock 2002:xiv,222; Olivier 2004:204-213). There is no doubt that it is largely by means of language that one generation passes on to the next its customs and beliefs, and by which members of a society come to be aware of their place in it. As a result, some of the major disciplines studying society and man's position in it are sociology, anthropology and ethnology. The area where they touch upon language is the true province of linguistic disciplines such as anthropological linguistics, sociolinguistics, and ethno-linguistics.

It is believed that the focus of this study the 'Posuban', which is a significant feature in most Fante communities presents to the mind something different from itself, but which may be meant to speak and remind others of some important principles and values of individuals, groups or the whole society. Cultural materials could therefore be seen to prescribe thought and behaviours of people. However, the essence of symbolization lies in the recognition of one thing as representing or standing for another and the relation between them is normally being that of concrete to abstract, particular to general as Carlyle (1987) holds that in symbol there is both concealment and revelation. Symbolization is a universal human process and very pervasive in communication. Accounting for the universality of symbols, Durkheim argues that a society keeps its value system through their use; that is the symbols stand for their revered values just like Posuban which are respected by communities that have it for various reasons. Without the Posuban, the values and some important aspect of the societies will be threatened. Data collected from the three communities of Amamoma, Apewosika and Kwaprow shows a significant aspect of cultural and linguistic traditions of the three communities. 


\section{Purpose of the Study}

The study sought to find out the relationship between the interpretations of colours and symbols on the Posuban and the world-view of the group of people that share the culture. The interpretation of the inscriptions on Posuban as an object of material culture and identity was also looked at. This is important because though Posuban has existed in the Fante culture for so many years, people merely regard it as shrines.

\section{Research Questions}

1. What are the interpretations of colours, and the interpretations of the symbols on the Posuban?

2. What are the interpretations of the inscriptions on Posuban as an object of material culture and how does Posuban help in the maintenance of culture and identity in these three communities.

\section{The Concepts of Language and Culture}

There are different views about the concept of culture and as a result its definition. But for the purpose of this study, the following is preferable. The Merriam-Webster's College Dictionary defines culture as 'the integrated pattern of human knowledge, belief and behaviour that depends upon man's capacity for learning and transmitting knowledge to succeeding generations'. Another usage in the same dictionary stresses the social aspect of culture and defines it as 'the customary beliefs, social forms, and material traits of a racial, religious or social group'. For the English anthropologist, Edward Burnett Tylor, "Culture is that complex whole which includes knowledge, belief, art, morals, law, customs and any other capabilities and habits acquired by man as a member of society" (As quoted in Katan 1999, p. 16). From the above definitions of culture it can be noted that one of the central elements in them is that culture is realized within society or a social group and the elements of culture includes art or material traits. Additionally, there is no society without language (verbal and non-verbal), in fact, most probably the most important instrument of socialization that exists in all human societies and cultures is language. This observation may be the reason why it is difficult to delineate language from culture. The complex relationship between language and culture has also been expressed by Kramsch (2000). He states that "when language is used in contexts of communication, it is bound up with culture in multiple and complex ways". He explains three situations where language expresses culture, embodies culture and symbolizes culture. Kramsch's assertion confirms how language, (verbal and non-verbal) and culture are inseparable and how language has proved to be the best tool with which human beings could express most of their feelings, needs, experiences and attitudes, and at the same time, entrap the knowledge and traditions of the time to remain available not only for the next generations of the same speaking community, but for other nations and ethnicities.

\section{Material Culture}

Prown (1982) defines Material Culture as the study through artifacts of the beliefs, values, ideas, attitudes, and assumptions of a particular community or society at a given time. The term material culture is also frequently used to refer to artifacts themselves, to the body of material available for such study. Gblerkpor (2011) also refers to material culture as "the physical object world around us. It may include our staple foods and cuisines, architecture, landscape, bodily ornaments, art forms and ceramic vessels". He adds that, "it may include natural or cultural features, monuments and objects/artifact". I shall restrict the term to mean the study and refer to the evidence simply as material or artifacts simply for the sake of the purpose of the study and also for clarity.

Material culture as explained by Prown (ibid) is singular as a mode of cultural investigation in its use of objects as primary data, but in its scholarly purposes it can be considered a branch of cultural history or cultural anthropology Prown (1982). It is a discipline rather than a field. In this, material culture differs from art history, for example, which is both a discipline (a mode of investigation) in its study of history through art and a field (a subject of investigation) in its study of the history of art itself. Material culture is comparable to art history as a discipline in its study of culture through artifacts. As such, it provides a scholarly approach to artifacts that can be utilized by investigators in a variety of fields. In practice it consists of subfields investigated by specialists, cultural geographers or historians of art, architecture, decorative arts, science, and technology. Material culture as a study is based upon the obvious fact that the existence of a man-made object is concrete evidence of the presence of a human intelligence operating at the 
time of fabrication. The underlying premise is that objects made or modified by man reflect, consciously or unconsciously, directly or indirectly, the beliefs of individuals who made, commissioned, purchased, or used them, and by extension the beliefs of the larger society to which they belonged. The term material culture thus refers quite directly and efficiently, if not both to the subject matter of the study, material, and to its purpose, the understanding of language and culture. This makes studying Posuban as a material culture relevant.

\section{Posuban as an object of material culture}

Posuban is a major significant feature in most Fante communities. Aggrey (1978:34) states it more clearly that 'any Fante community which does not have Posuban is a new community'. There are two schools of thought surrounding the term. One school has it that, the term Posuban is from these morphemes po which means 'sea', su which means 'water' and ban which means 'wall'. The three together mean'walled sea water'; 'a wall around sea water'. The other school has it that, the term is from pia-su-ban. Pia means 'chamber' su means 'type' ban means 'wall' making 'chamber type wall'. Literally, it means a type of room like chamber. Record has it that, Posuban was a small house built by the Asafo (warriors) in the likeness of a chamber as in (chamber and hall) just like their various rooms to house their equipment of war and regalia. Because it was modeled after their rooms, it was named as such, 'a type of a chamber'. But the term became corrupted as 'Posuban'. Posuban then became a place where the leaders of the Asafo met for posu (deliberations). Eventually, the term posuban came to replace pia-su-ban. I find the second interpretation of the term more plausible because some Posuban have apartments just like the description of the term. Again, it is a place that the Asafo met for deliberations just like what the term is describing. Data collected about Posuban, showed that it is still the place that members of the communities meet to receive visitors and for other programs as well as for the storage of their regalia. I will not align myself with the 'walled sea water theory', the first school because it makes Posuban a feature of the coastal areas only. Again, the $s u$ in the term which is translated as 'water' does not really match with $n s u$ which is the original translation of water. It rather matches with 'character' or 'type' as it is in the second theory. All these make the first theory less plausible.

Posuban is considered a material or an element of material culture because, it is a man-made artifact which communicates the beliefs, ideas, values and world-view of a people. It is a small house built by the Asafo for the storage of their regalia and other war equipment. Posuban of the early days was a tree with a cane fence around it and a medicine mound. The tree depicted a female guardian spirit and this was seen in the sacred flags of each Asafo company. But in modern times, probably because of fashion and tourism purposes, Posuban is built with cement blocks, well designed and decorated. It is mostly painted with the colours of the Asafo Company, it also has the name of the Asafo on it and other symbols; sometimes animals, drawings of man, gong-gong, trees and many other inscriptions. All these inscriptions and symbols communicate the beliefs, values, ideas, attitudes, and assumptions of the Asafo Company in particular and the community in general. The Posuban signified power; it showed that there were warriors and military units in the communities who were responsible for the defense of the community and consequently, it represents protection both spiritually and physically. Due to its significance, Posuban in the olden day were put at the outskirts of towns but today, most of them are seen to be at the centre of towns.

\section{Theoretical Framework and some Related Studies}

As a framework for analysis and interpretation, the theory of semiotics was used. Semiotics, which is seen as a branch of linguistic anthropology is the science of signs and signification. The two major founders of semiotics/semiology are the American philosopher C.S. Peirce (1839-1914) and the Swiss linguist Ferdinand de Saussure (1857-1913) (Blonsky 1991, Berger 2004 and Olaoye 2008). Peirce and de Saussure both based their theories on the fundamental distinction in the sign between the signifier and the signified although there is a slight difference in their theories.

De Saussure's division of the sign into two components, the signifier (or "sound-image") and the signified or ("concept"), and his suggestion that the relationship between signifier and signified is arbitrary were of crucial importance for the development of semiotics and in studying Posuban. Peirce, on the other hand, focused on three aspects of signs: their iconic, indexical, and symbolic dimensions. The meanings embodied in the Posuban are the signified. Posuban is symbolic and it could be iconic. Semiotics which is the study of symbols and their communicative meaning has made Posuban an interesting and intriguing 
mode of communication. Posuban and its colours, symbols and inscriptions are symbolic, iconic and symptomatic, and it is open to diverse interpretations and meanings.

Some works have been done on material culture but the concentration has been on the historical/archaeological aspect more than the linguistic aspect. Therefore, most of the review will be on works of historical/archaeological more than the linguistic value. This work therefore, seeks to fill the linguistic gap or serve a paradigm shift.

\section{Asafo Company}

Seeing the Krobo Mountain as a material or artifact strengthens the view that the Posuban is also a material or artifact. It has the ability of "semiotic distinction which can be translated into a language of signs, symbols and iconography" which communicates meanings about the Fante people in a non-verbal way. But one cannot study Posuban without mentioning the Asafo Company because, the Asafo features prominently in Fante oral traditions and history and they are the 'owners' of Posuban. Aggrey(1978:33-35) giving an account of the Asafo wrote that, "Posuban in every Fante community signifies the presence of Asafo Company, it is a place that they meet and decide on strategies to adopt for war, it is a shrine for the Asafo god". The Asafo Company believes that they receive blessings from the Posuban for victories in war; it is also a place where they converge before every journey is made. Although Asafo is no more fashionable, (probably because its functions have been taken by the police and other security services, also, tribal wars are not common these days. Modernization could also be a factor) they are still a significant factor in the Fante story/history. Their personalities, Posuban, song texts, drumming instrument and regalia are still significant to the communities in which they are built and scholars. Acquah (2010) for instance has done a study on the Repertoire of Tropes: A Study of Akan Asafo Song Texts. Therefore, this work also studies the Asafo but in the context of the Posuban concentrating on its linguistic value.

\section{Methodology}

This research used first-hand information and observation of the Posuban in the three communities to enrich theoretical conceptualizations of how cultural meanings are created and sustained. The empirical approach examines practices of everyday life in specific context using cultural theories that describe the formation and transmission of cultural ideas, identities and meanings.

The study employed a qualitative research design. Observation was one of the instruments used to collect data for the study. The researcher critically observed the Posuban in the three communities in relation to their colour, images/drawings and inscriptions. The specific colours, images/drawings and inscriptions were written down and pictures were also taken of the various Posuban. Interviews were conducted in all three communities of Amamoma, Apewosika and kwaprow and recorded. This was done to find out indigenes' views about posuban and its related information. With this, all interviewees were asked a standard list of questions in a standard order. The interviews were conducted in the local language (Mfantse), recorded with a phone recorder while the phone was on flight mode.

The participants were chosen from Amamoma, Apewosika and Kwaprow. All these communities are located around the University of Cape Coast, Ghana. Altogether 24 informants were sampled. This number was distributed over the three communities. This means that eight informants were selected from each of the communities. Out of these eight, two represented each of the age categories. The purposive sampling procedure was used to do this selection. The informants were chosen based on traditional linguistic knowledge; elders with empirical knowledge of Mfantse; students and lecturers involved in the teaching and studying of Mfantse.

\section{Results and Discussion Posuban and colours}

Data collected shows how colour can be a critical factor in communication and the power that it can exert on perception in various cultures. Colour was seen as a valuable resource in each of the community studied. These colours are seen in the flags of the Asafo and are used to paint the Posuban, the colours mark identity. Colours encountered were red, black and white and each of them has their unique significance. These colours seem to suggest the basic colour terms of the Fantes because their descriptive meaning seems to be related to the physical world of everyday experience. In the case of Amamoma and Apewosika, red is 
their colour, for them, red signifies seriousness, power, courage, impulsiveness and physical prowess. They believe that war is a serious thing which requires power, courage and seriousness. As soldiers, they must always be on guard and be ready for war or their enemies. Hoisting red flags tells their enemies how serious they are. In the case of Kwaprow, their colour is white. For them, white signifies victory. For they always come out from war victorious. As a result, 'anytime they hear of war, they laugh'. There is a black colour under the white; they believe that, the black protects the white from dirt. It is again interpreted that, there are some unseen spirits who are always behind them and they help them to achieve their victories. These colours encourage hard work and enable the users to control their environment. Thinking along with Kramsch (2000:22), the above interpretation seems to suggest that, 'the way in which language strengthens social power makes some uses of cultural signs seem legitimate'. Although colour terms may have negative meanings, these communities attach themselves only to the positive interpretations of colours probably to wish for only good things. The results of this work provide evidence which supports the view that the meanings of colour have accordingly varied based on certain universal identifiable human experience. This is because, the Akans used to have only three colour terms (Osam 1998); fitaa/fufuo/(w) for white and all bright colours, tuntum for all dark colours (black, brown, blue, green etc) and kJk]] for red and its family. But now, there are colours like 'bruw' for blue, 'akok] angwa'for yellow, 'ahabanmon' for green, akok]bin for brown and many other new colour terms. These might have come as a result of foreign influence. I am tempted to think that, there are mechanisms for expanding colour and their meanings, as well as the reasons why some colour terms appear to have negative and positive meanings.

\section{Posuban and Symbols/Drawings}

Drawings and statues on Posuban are truly embodiment of Fante culture which communicates. The Amamoma Posuban has no drawings on it because for them, the Posuban speaks for itself but that of Apewosika and Kwaprow do. The drawings on the Apewosika Posuban are that of two men, with one holding a syringe-like device and a plate of food with the other one bent towards the ground. This drawing has the writing: ibedzidzianaasaanaad[eb[saanaedzidzi? (Will you eat before you douche or you will douche before you eat?). This saying is proverbial, it is explained that there are times that man faces challenges, where he has to choose between two equally important options, when it happens like that what does one do.? Relating this to war, it is believed that the people of Apewosika are so kind that when they capture their enemies in war, they give them options to choose from. Either these 'enemies would want to be their subjects or they would want to die'. Whether you join them or not, you have been taken captive.

The Kwaprow Posuban as well has four symbolic drawings on it.

i. There is the drawing of four footpaths intersecting with two lions at the intersection.

ii. It also has a drawing of an elephant leaning against a tree with the inscription:\} sonwoenntumAkyebi no, ]dze no y[[ ne naba ('when the elephant could not fell the 'akyebi' tree, the elephant took akyebi for a sibling').

iii. A clock with the time at 4:00 o'clock.

iv. Three sets of gong-gong.

Interview conducted revealed that, all these drawings depict something significant. The intersection of the four footpaths with two lions at the centre signifies a fierce people who are always guarding their territory. Whichever corner that the enemy may come from, they will be grabbed. The elephant leaning against the 'akyebi' tree signifies that, strength and power does not belong to the fat only. In other words, 'the best way to save yourself from the blows of the mighty is to befriend them or take them as siblings'. The clock also shows the exact time that one of their wars was fought. Lastly, the three sets of gong-gong represent the Asafo weapons and instrument.

Considering these metaphors, it is seen that, they provide the schemata through which its people understand the world. This shows that language and images are integrated in multi-semiotic texts like the Posuban. It also shows that the Fantes have diverse ways of communicating but as said earlier, it takes only an interpretive mind to understand, they have a unique way of seeing things, using images to communicate is just like being multi-lingual, in the sense that, multi-lingualism saves the speaker from trouble, he 
switches code at any time to save himself and or to identify himself with the language of power at a particular moment.

\section{Posuban and Inscriptions}

The inscription on the Amamoma Posuban, also the name of the Asafo Company reads 'BosompoB]too Abo'. ('the see god came to meet the rocks'). The one at Apewosika reads; ' 'sonB]f]n B[y[ deAdoa no, nnaAdoaAyewHabanAse'. (by the time the elephant grows lean to the size of 'adoa' (an animal in the antelope family), 'adoa' would be lost in the bush.

Kwaprow's inscription goes like 'JdomankomaAnk]bea Y[tseko a Y[serew'. (we laugh when we hear of war').

The above inscriptions are seen to be proverbial and therefore metaphorical. From a linguistic standpoint, a proverb is "a phonological, syntactic, semantic, pragmatic, and, some would add, a semiotic (complex sign) entity. There is no question that all proverbs exhibit regularities on one or more of these levels"(Honeck 1997:11-12).Content of proverbs are observed life situations and experiences, beliefs, social views and attitudes of a people. A person who speaks in proverbs is considered wise and has knowledge of his culture. So, inscribing these words in proverbs shows how Fantes respond to critical circumstances. There is more than one interpretation to a proverb. This feature of proverb makes it a 'life saving tool'. For example, a person who understands the inscriptions on the Kwaprow Posuban will be more careful in dealing with the people of Kwaprow in terms of war and its related activities. The inscription tells that the Kwaprow people are people who become happy at the hearing of war and for that matter they are to be feared. The inscription shows their attitude towards war and danger, this inscription corroborates their white colour because once they laugh at the hearing of war it means they are always victorious. The inscriptions on Amamoma and Apewosika Posuban are more of castigations and insinuations between the two communities. Information gathered from interview conducted showed that the people of Amamoma and Apewosika are at loggerheads and this is evident in the inscriptions. 'BosompoB]too Abo'. ('the see god came to meet the rocks' in other words, the rocks were in existence before the sea was created). Apewosika developed out of Amamoma so that inscription on the Amamoma Posuban is a way of telling the people of Apewosika that no matter how large the community (sea) is, the rocks (Amamoma) are older than the sea (Apewosika). Then Apewosika too has; ' $J \operatorname{sonB}] f] n$ B[y[ deAdoa no, nnaAdoaAyewHabanAse'. (by the time the elephant grows lean to the size of 'adoa' [an animal in the antelope family], 'adoa' would be lost in the bush). This is also a way of the people of Apewosika telling the people of Amamoma that, by the time the Amamoma community (the elephant) grows to the size of Apewosika (adoa),Apewosika will be far advanced. This is quite ironical. This shows that the Fantes through proverbs can communicate a lot of information. The different proverbs show that Fantes employ the proverbs differently to express emotions, values and their knowledge about nature and its relationship with man.

\section{Conclusion}

The study has analyzed and interpreted Posuban as an element of material culture among the Fante people of Amamoma, Apewosika and Kwaprow. From the linguistic perspective of colours, drawings/images and inscriptions it was revealed that, Posuban tells a lot about Fante peoples' history, beliefs, values and their character which remain otherwise inaccessible except through impersonal records. It can be said that Posuban is a symbol which communicates meanings just like verbal languages do. It provides representative source of information but it takes only an interpretive mind to understand it. From linguistic and anthropological point of view, Posuban among Fantes is a semiotic sign which marks identity, power and security. Posuban showcases rich cultural heritage of the Fantes. It promotes unity, encourages a sense of belonging, engenders the spirit of co-operation, helps in instilling discipline, prevents criminal tendencies, and tends to remold and rebrand people. Posuban is emblematic, iconic and indexical.

The research has opened up many complex areas with regards to the study of material culture. It is therefore recommended that, more studies should be done on Posuban. This is because, today, Posuban is merely considered as shrines but there are a lot of scholarly information that could be obtained from this Posuban for studies in so many disciplines. This will go a long way to increase scholarly work in the studies in material culture. Researchers can build on the current research in order to expand the literature in the area. 


\section{References}

[1] Aggrey, S. J.E.K. (1978)Asafo.Tema: Ghana Publishing Corporation.

[2] Alcock, S. E. (2002). Archaeologies of the Greek Past: Landscape, Monuments and

Memories.

Cambridge: Cambridge University Press.

[3] Blonsky, M. (Ed) (1991).On Signs. Baltimore: The Johns Hopkins University Press.

[4] Buchli, V. (2004).Material Culture: Critical Concept in the Social Sciences. New York, Routledge.

[5] Gblerkpor, N. W. (2011). Material Culture and Ethnic Identity: The Case of the Krobo, Ghana. Legon, Accra: Sub-Saharan Publishers. Identity Meets Nationality: Voices from the Humanity pp 149-170.

[6] Glassie, H.(n.d) Folkloristic study in the American Artifact In Handbook of American Folklore, edited by Richard Dorson, forthcoming.

[7] Honeck, R. P., (1997). A Proverb in Mind: the Cognitive Science of Proverbial Wit and Wisdom. Mahwah, NJ: Lawrence Erlbaum Associates, Inc. Available from: http://books.google.com/books [Accessed 10 $10^{\text {th }}$ January, 2014]

[8] Kramsch, C. (2000). Language and Culture, New York: Oxford University Press.

[9] Levi-Strauss, C. (1963) Structural Anthropology. New York: Basic Books.

[10] Merriam-Webster's Collegiate Dictionary (12th Edition).Merriam-Webster Editorial Staff, Method. Chicago: The University of Chicago Press.

[11] Olaoye, A.A (2008).Nigerian Dress Culture: A Linguistic and Anthropological Communication Tool.Abuja, Nigeria, Department Of Linguistics and African Languages, University of Abuja.

[12] Olivier, L. (2004). The Past of the Present: Archeological Memory and Time. Archeological Dialogues 10 (2): 204-213

\section{APPENDIX A}

\}domankoma. ... a term which connote creator or (from creation)

Akyebi. it is a small but a very strong tree in the bush

Amamoma............................. is a village around the University of Cape Coast. The term means meandering or to meander. It is from the words aman-aman

Ank]bea..................................'ank]' means does not move. 'Bea' means place. The term 'ank]bea' refers to the division of warrior who do not go to the battlefield but stay home to take care of home affairs. They target enemies who will come to their town to fight. In short, they monitor the affairs of the home.

Asafo...................................warriors

Ban it is a wall or a fence around something

Bosompo a name given to the sea or the sea god

Kõ. war

Kwaprow ............................... it is a name of a town in Cape Coast. It is from the terms $\mathrm{k}]$ (go) and apr]w (around)

Pia. chamber or inner room

Posu .deliberations

Posuban small houses used by the Asafo for storage of arms and company regalia, but are now elaborate concrete shrines in most areas of Fante settlements. 


\section{APPENDIX B. PICTURES OF POSUBAN}
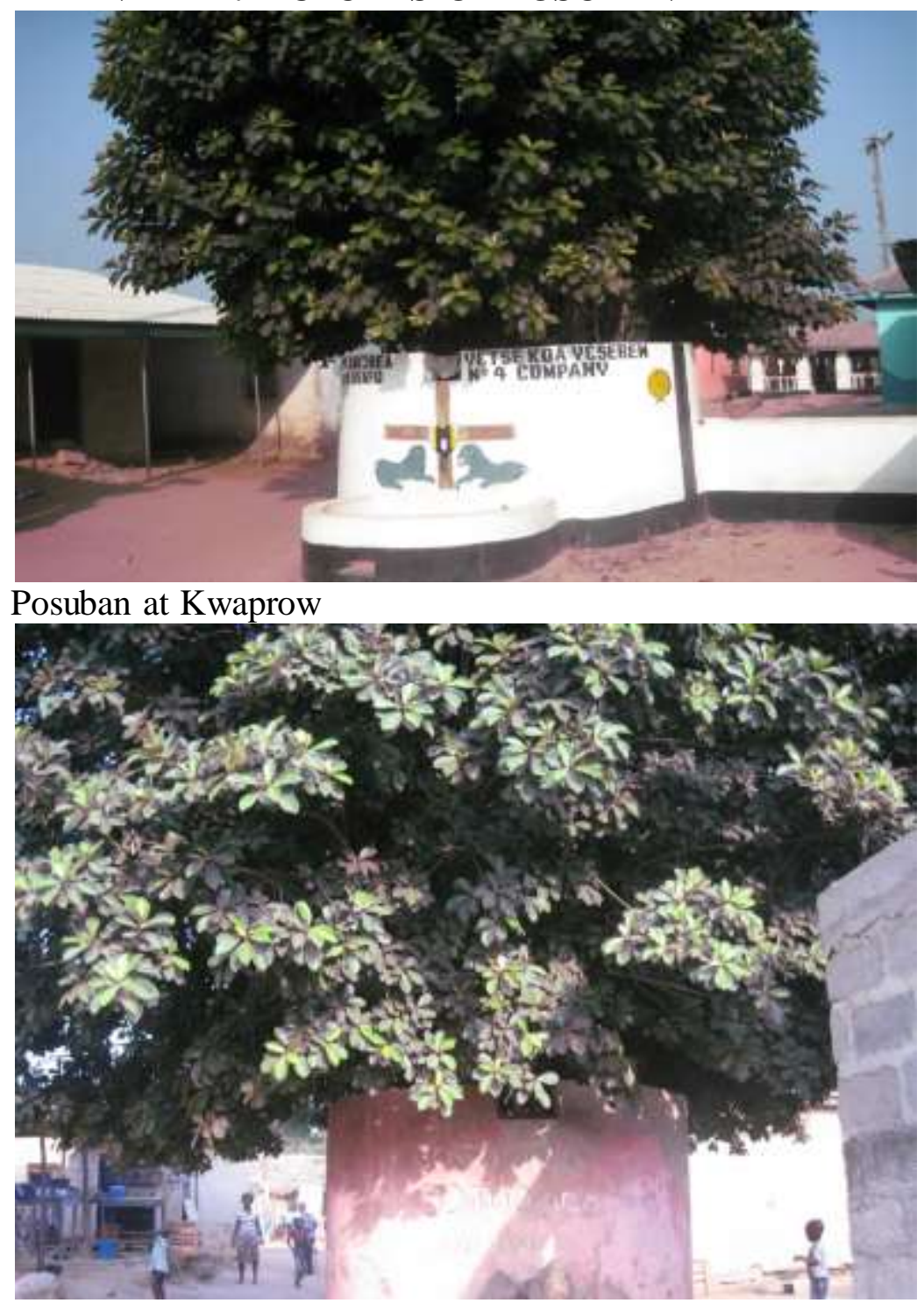

Posuban at Amamoma

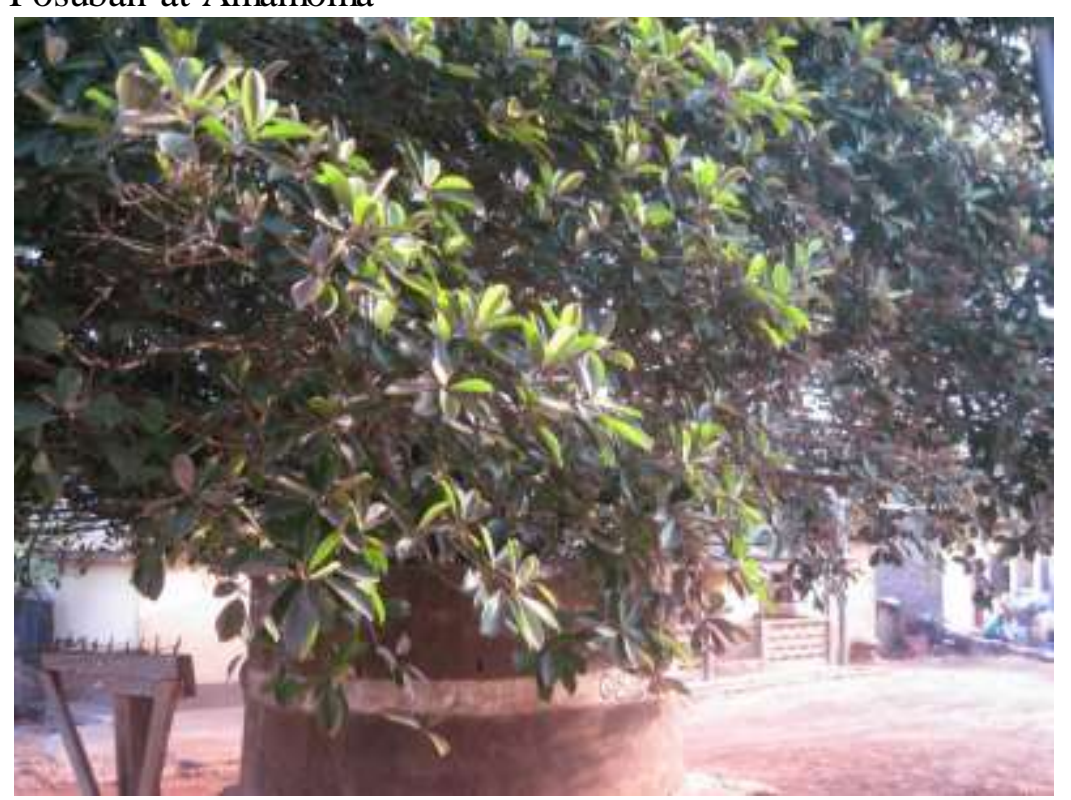

Posuban at Apewosika 


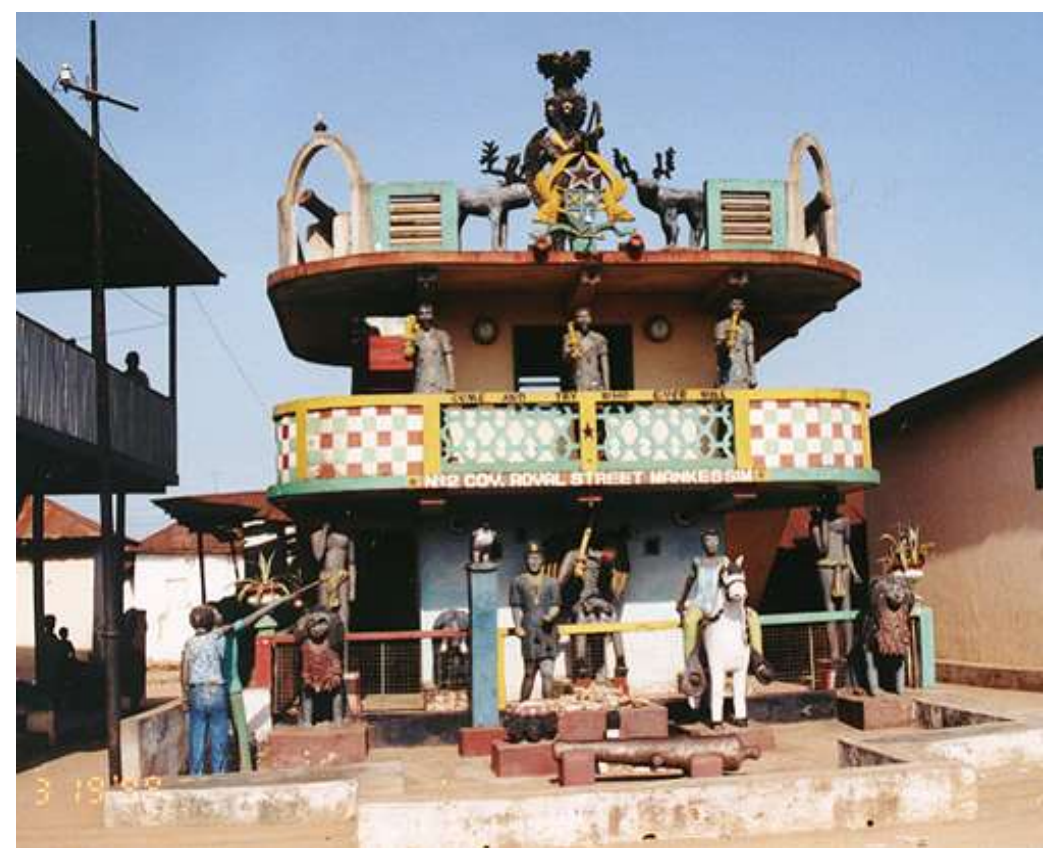

Posuban at Mankessim 